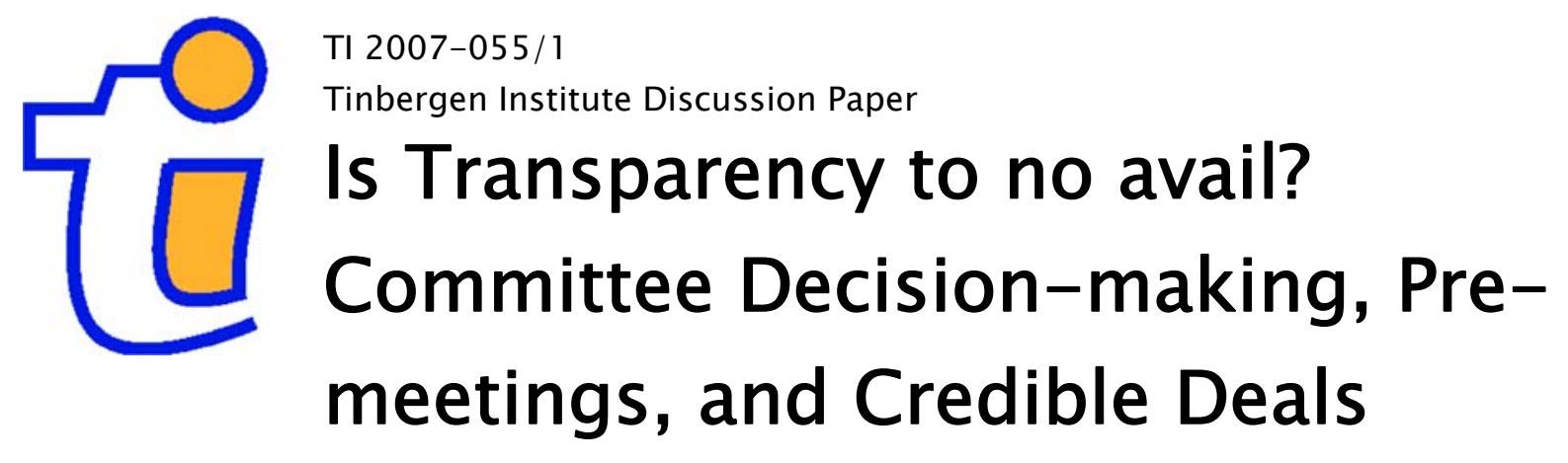

Otto H. Swank

Bauke Visser 


\section{Tinbergen Institute}

The Tinbergen Institute is the institute for economic research of the Erasmus Universiteit Rotterdam, Universiteit van Amsterdam, and Vrije Universiteit Amsterdam.

Tinbergen Institute Amsterdam

Roetersstraat 31

1018 WB Amsterdam

The Netherlands

Tel.: $\quad+31(0) 205513500$

Fax: $\quad+31(0) 205513555$

Tinbergen Institute Rotterdam

Burg. Oudlaan 50

3062 PA Rotterdam

The Netherlands

Tel.: $\quad+31(0) 104088900$

Fax: $\quad+31(0) 104089031$

Most TI discussion papers can be downloaded at http:/ /www.tinbergen.nl. 


\title{
Is transparency to no avail? Committee decision-making, pre-meetings, and credible deals.*
}

\author{
Otto H. Swank \\ Erasmus University Rotterdam \\ and Tinbergen Institute
}

\author{
Bauke Visser \\ Erasmus University Rotterdam \\ and Tinbergen Institute
}

July 17, 2007

\begin{abstract}
Transparent decision-making processes are widely regarded as a prerequisite for the working of a representative democracy. It facilitates accountability, and citizens may suspect that decisions, if taken behind closed doors, do not promote their interests. Why else the secrecy? We provide a model of committee decision-making that explains the public's demand for transparency, and committee members' aversion to it. In line with case study evidence, we show how pressures to become transparent induce committee members to organize pre-meetings away from the public eye. Outcomes of pre-meetings are less determined, more anarchic, than those of formal meetings, but within bounds. We characterize feasible deals that are credible and will be endorsed in the formal meeting.
\end{abstract}

Keywords: Committee decision-making, reputational concerns, transparency, pre-meetings, deliberation

JEL codes: D71, D72, D82

\footnotetext{
*We are very grateful to Francesco Lippi, Ellen Meade, and Peter Norman Sørensen, for their comments and questions on Transparency and Pre-meetings, a TI discusssion paper (06-051/1) that contained a very early version of the theory developed in the present paper. That discussion paper also presented a case study of the FOMC. The case study can now be found in Swank, Swank, and Visser (2007). E-mail: SWANK@FEW.EUR.NL and BVISSER@FEW.EUR.NL
} 


\section{Introduction}

Transparent decision-making processes are widely regarded as a prerequisite for the working of a representative democracy. One reason is that transparency facilitates democratic accountability. Another reason is that when representatives make decisions behind closed doors, the citizens may suspect that their interests are not fully promoted. Why else the secrecy? Against the background of the potential advantages of transparency, it is hardly surprising that legislation, like the Freedom of Information Act in the United States, tries to foster transparency. More generally, "over thirty countries have passed Open Government codes, which establish the principle that a citizen should be able to access any public document" (Prat, 2005, p.2). However, it is not always clear that this type of legislation succeeds in safeguarding transparency. Stiglitz (1998) was shocked by the focus on secrecy in the Clinton administration when he served as the chairman of the Council of Economic Advisers. Roberts (2006) documents various ways in which governmental bodies in, among others, the United Kingdom and Canada have adapted to demands for more transparency, ranging from formal challenges through changes in record-keeping to outright failure to create records.

Even when a process is formally transparent, it is not always the case that the actual decision-making process is truly open. Illustrative in this respect is Greenspan's response to the pressure from U.S. Congress that the Federal Open Market Committee (FOMC) should become more transparent. He conjectured that the request of Congress would induce an important change: "[a] tendency would arise for one-on-one pre-meeting discussions, with public meetings merely announcing already agreed-upon positions or each participant to enter the meeting with a final position not subject to the views of others" (Greenspan, as quoted in Meade and Stasavage forthcoming, pp. 18-19). When discussing decision-making within the European Council of Ministers, Stasavage (2005) also points to the possibility that more transparency may lead to more backroom discussions or deals over lunch.

This paper addresses two main questions. The first question is why decision makers wish to deliberate in private, or why, as Stiglitz (1998, p.17) puts it, "there remains an obsession with secrecy despite America's social consensus in favor of openness". The second question goes one step further. Suppose that formally a 
decision-making process is transparent, but that a decision is pre-cooked behind closed doors. What can we say about the decision being taken?

To answer both questions we develop a model that describes a situation where on behalf of the public a committee has to make a binary decision, deciding for change or maintaining the status quo. Whether change or the status quo is the proper decision from the public's perspective depends on the consequences of the decision. At the moment the decision is made, these consequences are uncertain. Each member has a private view of the consequences. The more likely it is that someone is competent, the more likely it becomes that a member's view provides an accurate picture of these consequence. A member does not know whether he is competent or not, only that he is competent with a certain probability. A crucial feature of our model is that a committee member would like to take the decision that is best from the public's perspective, but also cares about how the public perceives his ability to foresee the consequences of a decision.

The decision is made in two stages. In the first stage, the communication stage, members discuss their views. In the second stage, the voting stage, the committee makes a decision through voting. Initially, we assume that whether the decision taken was the correct one from the public's perspective is not immediately apparent. Decisions on large infrastructure projects are an example. Once the decision has been taken, it may take years if not decades to find out whether the construction of tunnels, ports, and railway lines unlock an area or should be considered a waste. Also the consequences of changes in, say, the financing of the health care sector, the curriculum of schools, or the composition of the Army only become known years after the decision has been taken. As the consequences in these cases are not immediately apparent, the public cannot assess the decision-making competence of a committee member on the basis of the quality of his forecast.

In a truly transparent decision process, the public observes the exchange of views thanks to, say, the presence of cameras or the publication of verbatim transcripts. We show that members share their views and make decisions that are optimal from a social point of view. This desirable behaviour provides an explanation for the demand for transparency. Our analysis also hints at an explanation for why committee members are averse to transparency, and want to deliberate in private. As the public does not learn the proper decision, it forms a perception of the mem- 
bers' decision-making abilities by comparing their statements. Disagreement signals lack of competence, as competent members view the consequences of the project in the same way. As a result, committee members have an incentive to organize a pre-meeting. A pre-meeting can be used to collect all opinions, determine what decision suits the public best, but conceal disagreement from the public by showing a united front favouring the decision. By a pre-meeting, we mean a meeting without cameras and of which no minutes are kept, and that can be used, therefore, to freely exchange views. Lunches and dinners before official meetings are examples, but also a quick exchange in a colleague's office before entering the official, public, meeting.

We next assume that a secret pre-meeting is held and that the public is aware of this. At first glance, one may think that a transparent decision-making process where the decision is pre-cooked in a pre-meeting is equivalent to a closed process where the public does not observe how a decision is reached. There are two subtle differences, however. First, in a formal closed process there are rules that stipulate how decisions are made. One important rule is the voting rule, which determines how many votes are required for a change. Pre-meetings often do not take place within a formal framework. No document states their terms of reference, nor the voting rule to be used. Instead, custom, a person's rhetoric, prestige, and seniority may play an important role during the pre-meeting. The ability of a member to inflict damage on fellow members or to obtain his goal outside the pre-meeting may grant him power and limit the power of others. Second, deals made in pre-meetings have to be endorsed in the formal meeting. If, for example, in the pre-meeting members agree to form a united front and to vote for change, nobody should have an incentive to deviate from such an agreement in the formal meeting. To put it differently, deals made in a pre-meeting have to be credible.

To analyze the effect of pre-meetings on decisions we determine the range of feasible deals made in a pre-meeting that will be endorsed in the formal meeting. We briefly summarize our main results. Recall that members want to conceal disagreement to avoid reputational damage. It directly follows that committee members want to speak with once voice in the formal meeting. This will be part of a deal. Another part of the deal is the decision to be favoured in the formal meeting. An important result is that reputational concerns give incentives to distort that decision.

To study the credibility of a deal made in the pre-meeting, we analyze committee 
members' incentives to break the deal in the formal meeting. We argue that the only motivation to break the deal is to prevent a distorted decision. Moreover, we show that breaking a deal damages one's reputation. A direct implication is that the member who is least concerned about his reputation has the strongest incentives to break the deal. A member can break a deal in the formal meeting either by voting against the pre-cooked decision in the voting stage or by breaking the united front in the communication stage. A somewhat obvious, but important, result is that breaking the deal must alter the final decision. The loss in reputation has to be compensated by the benefit of a better decision. A direct implication is that unilaterally breaking the deal in the voting stage only makes sense when a decision for change requires unanimity. Relatedly, if a member breaks the deal in the communication stage, a sufficient number of members (the exact number depends on the voting rule) must respond to this by voting against the agreed decision. Committee members may be willing to vote against the agreed decision, because once a member has broken the united front in the communication stage, the reputational benefits from a distorted decision are lower. Out-of-equilibrium beliefs play an important role in members' decisions whether or not to support a deviating member. In general, the more distorted is the pre-cooked decision, the stronger is a member's incentive to deviate in the formal meeting or to support a deviating member. The formal meeting thus limits the deals that can be made in the pre-meeting.

Is transparency to no avail? Would it be better to leave a decision-making process closed, such that deliberation and voting in the formal meeting remain hidden from the public eye? A formal meeting is typically characterized by a voting rule. This adds determinacy to the outcome of the process. If imposing transparency gives rise to a pre-meeting, the lack of a voting rule in that meeting makes its outcome unpredictable. This we consider a drawback. Transparency, however, may be a good thing. The public can only benefit from the fact that deals that are struck in the pre-meeting have to be endorsed in the formal, public, meeting, as it tempers the enthusiasm for unwarranted decisions.

The next section discusses the related literature. Section 3 presents the model, and sections 4-6 contain the analysis. A number of extensions are discussed in section 7 . In section 7.1, we examine committee members' incentives to shun the 
pre-meeting. There are two important differences between skipping a pre-meeting and deviating in the formal meeting. First, by skipping the pre-meeting, a member does not learn the views other members hold. It will therefore be unclear whether it is worth to skip the pre-meeting. Second, staying away from a pre-meeting forces a member to anticipate what kind of deal the other members will make in his absence. Skipping a pre-meeting only makes sense if it weakens the incentives of the other members to distort the decision. We show that this is not always the case. In section 7.2, we examine the incentives to organize a pre-meeting if the public does observe the consequences of the decision. A statement that is confirmed by reality boosts a member's reputation, while a refuted statement hurts it. The inclination to organize a pre-meeting is still felt. A pre-meeting allows each member to form a better opinion and thus increases the likelihood of seeing his public statement confirmed by the actual consequences. Finally, in section 7.3 we show that a truly transparent process may lead to posturing if members know their own and each

others' levels of competence. This posturing leads to a distorted decision. A premeeting remains a useful tool to hide conflicting views.

\section{Related Literature}

Our paper is, to the best of our knowledge, the first to analyse pre-meetings. It contributes to the literature on the benefits and costs of transparent decision processes. There is a long history to this debate in the political science literature on democracy, see Stasavage (2007) for a concise overview. Transparency is needed for accountability and may increase the legitimacy of decisions taken. It has been recognized, though, that transparency may give rise to posturing. A delegate, rather than taking an action that he truly believes will further the interests of the constituents, may decide to act in accordance with what the constituents believe is the right action. This form of posturing stems from a delegate's desire to convince the constituents that he shares their preferences or ideology. Morris (2001) analyses these incentives in an advisor game. Stasavage (2007) studies the inclination of a delegate to use his vote as a signal of preference alignment in a group decision process. He shows that the incentive to do so is stronger in a transparent process than in a closed decision-making. 
Posturing may also result from a desire to come across as an expert who is able to ascertain the truth about something that is relevant to the constituent. In Fingleton and Raith (2005), there is uncertainty about the ability of a delegate to obtain information about the opponent's fallback option. If a bargainer cares about his reputation, open rather than closed negotiations may harm the constituent due to overly aggressive bargaining. The finding that a principal does not necessarily benefit from information on the action taken by an agent who wants to maintain a reputation for competence is also presented in Prat (2005). Levy (2007) analyses behaviour of experts in a voting game. Experts receive possibly correlated information about the state of the world. She finds that if correlation is weak or absent, a closed process induces members to favour the conventional decision, i.e., the decision that is a priori more likely or the one that requires the least unequivocal support. This decision acts as a safe haven as it obscures how members actually voted. This conformism bias disappears if correlation is strong. In this case, there is a bias to support the unconventional decision. The conformism bias also disappears in case of a transparent process.

Other implications of transparent processes have also been studied. Perry and Samuelson (1994) assume that open-door negotiations allow constituents to intervene if they are apprehensive about the way the negotiations are evolving. Such is not possible in case of closed-door negotiations, and this may well be beneficial. Gersbach and Hahn (2004) show that transparency improves selection and increases alignment of interests between delegates and constituents over time. ${ }^{1}$ Patacconi (2007) argues that the requirement to publish information that is used in political decision-making gives rise to information manipulation by politicians who care about re-election.

The issues of transparency in general and transparent decision processes in particular have been debated extensively in the realm of central banking. ${ }^{2}$ Two contributions are especially relevant for the present paper. Meade and Stasavage (forthcoming) and Swank, Swank and Visser (2007), using data gathered by Meade (2005), discuss the changes in the nature of the deliberations at the FOMC that resulted

\footnotetext{
${ }^{1}$ Matozzi and Merlo (2007) stress that selection may give rise to sorting of individuals between politics and private business.

${ }^{2}$ Geraats (2002) provides a taxonomy of dimensions in which a central bank can be transparent.
} 
from the pressure of U.S. Congress on the FOMC to publish verbatim transcripts with a five-year time lag. Meade and Stasavage argue that this pressure has strengthened the incentives to herd in a sequential decision-making process. Swank, Swank and Visser stress that it has shifted the locus of the real debate, away from the formal FOMC meeting to pre-meetings.

This paper also contributes to the literature on committee decision-making. That literature has focused on the question whether a group makes better decisions than a single individual. This question has often been analysed using the jury metaphor in which jurors have to decide on the verdict of the accused. Jurors care (possibly to varying degrees) about type I and type II errors. Li, Rosen and Suen (2001) show that conflicts of interest provide a rationale for voting rules. The quality of committee decisions depends on the specific voting rule used (Feddersen and Pesendorfer 1998, Ladha 1992, Young 1988) and on the number of jurors (Mukhopadhaya 2003 and Persico 2004). The situation we describe is not analogous to a jury problem. We view decision-makers as experts who also care about their perceived decision-making ability. This is plausible when members are selected because of their expertise, something that does not apply to jurors. Unlike most studies on jury decision making, we describe situations in which members deliberate before casting a vote. Coughlan (2000) is one of the first to show how the possibility of even minimal communication changes the role of voting rules. ${ }^{3}$ Austen-Smith and Feddersen (2002) and Visser and Swank (2007) argue that the choice of voting rule should balance the quality of deliberation and the alignment of interests of the decisive voter with those of the public. ${ }^{4}$ Dessein (2007) and Wernerfelt (2007) consider the way in which the committee structure affects the intensity and quality of deliberation. Ottaviani and Sørensen (2001) study the influence of herding on the quality of debate, and the desired order of speech. Caillaud and Tirole (2007) analyse how a sponsor of a project can persuade a group by deciding who to approach first, who next.

Recently, economists have analysed group polarization and groupthink. In the psychological literature, these phenomena are often presented as instances of 'process loss' from which groups may suffer. ${ }^{5}$ Eliaz, Ray and Razin (2006) and Sobel (2006)

\footnotetext{
${ }^{3}$ See also Geradi andYariv (2006).

${ }^{4}$ Meirowitz $(2004,2005)$ compares the effectiveness of debate and transfers in inducing information revelation.

${ }^{5}$ See, e.g., Aronson, Wilson and Akert (2005).
} 
discuss group polarization, the observation that individuals as a group may advise or take a decision that is more extreme than any member would advise or take individually. Especially Sobel insists that polarization may be an outcome that is not only rational but even first-best. Groupthink, rather than referring to the outcome of a group process like polarization, is a hypothesis about behaviour taking place while deliberating. It would be a source of flawed decisions. Coined by Janis (1972), it refers to a tendency to seek concurrence in the group with the aim of maintaining the approval of fellow members. It would lead to, among others, the presentation of manipulated information that favours a particular decision, a lack of discussion about that information in the presence of doubts about its validity, and a united front to the outside world in support of the final decision. In Visser and Swank (2007), we view these phenomena not as a result of groupthink but as the outcome of deliberation and voting by a group of members who care both about project value and about their perceived decision-making ability. ${ }^{6}$

\section{The Model}

On behalf of the public, a committee of $n$ persons, $i \in I=\{1, \ldots, n\}$ has to decide between maintaining the status quo, $X=0$, and implementing a project, $X=$ 1. By normalization, status quo delivers a payoff equal to zero. If the project is implemented, the project payoff to each member (and the public) equals $p+\mu$. The parameter $p$ is the ex ante expected payoff from $X=1$. The stochastic term $\mu$ captures that the state of the environment, and therefore the payoff from $X=1$, is uncertain. We assume that $\mu \in\{-h, h\}$, with equal prior probability. Moreover, we assume that (i) $p<0$, implying that the committee has a bias against project implementation; (ii) $p+h>0$, implying that the socially optimal decision depends on the state of the economy.

At the beginning of the game, each member $i \in I$ possesses a private signal about $\mu, s_{i} \in\left\{s^{b}, s^{g}\right\}$. A signal refers to a member's assessment, forecast or view of $\mu$ ( $b$ is bad and $g$ is good). Whether this signal is informative depends on a member's type, $t_{i}$. Each member can be smart or dumb, $t_{i} \in\{s m, d u\}$. The prior probability that a

\footnotetext{
${ }^{6}$ Our explanation is therefore more in line with Kramer's account of the decision processes that Janis analyses (1998).
} 
member is smart equals $\pi$. A smart member has a fully informative signal about $\mu$. His view on $\mu$ is flawless, $\operatorname{Pr}\left(\mu=h \mid s^{g}, s m\right)=\operatorname{Pr}\left(\mu=-h \mid s^{b}, s m\right)=1$. A dumb member receives an uninformative signal: $\operatorname{Pr}\left(\mu=h \mid s^{g}, d u\right)=\operatorname{Pr}\left(\mu=h \mid s^{b}, d u\right)=$ $1 / 2$. He does not learn anything new about the expected value of the project. A member does not know his own competence, only the probability with which he is smart, $\pi .^{7,8}$ The ex ante probabilities of $\mu$ and the prior probability $\pi$ are common knowledge.

Preferences of committee members over the alternatives consist of two parts, one reflecting the public interest, and one reflecting reputational concerns. Specifically, member $i$ 's preferences are represented by:

$$
\begin{aligned}
U_{i}(X=1) & =p+\mu+\lambda_{i} \hat{\pi}_{i}\left(\Omega_{1}\right) \\
U_{i}(X=0) & =\lambda_{i} \hat{\pi}_{i}\left(\Omega_{0}\right),
\end{aligned}
$$

where $\hat{\pi}_{i}$ denotes the posterior belief held by the 'market' or the 'public' that committee member $i$ is smart. We refer to this belief as member $i$ 's reputation. This reputation is based on observed and inferred information, $\Omega_{X}$. The fact that the information set is indexed by the decision on the project, implies that the public observes at least this decision. It does not observe the state of the environment $\mu .^{9}$ Depending on the way the decision-process is organized the market may also observe how the project decision is arrived at. The parameter $\lambda_{i}$ measures how much committee member $i$ cares about his reputation. Committee members have homogenous preferences as to the project, but differ in the weight they attribute to their reputation, $\lambda_{1}<\lambda_{2}<\ldots<\lambda_{n}$. These weights are common knowledge. We use (1) and (2) with $\lambda_{i}=0$ to represent the public's interest.

The decision on the project is made in two stages. In the first stage, the communication stage, each member sends a message, $m_{i} \in\left\{m^{b}, m^{g}\right\}$. By this we mean that a member presents an analysis of $\mu$. In the second stage, the voting stage, the messages sent are common knowledge, and the members vote on the project, $v_{i} \in\left\{v^{b}, v^{g}\right\}$, where $v_{i}=v^{b}\left(v_{i}=v^{g}\right)$ denotes that $i$ votes against (in favour of)

\footnotetext{
7 "Dumb" may mean "less smart". What matters for the results is that a smart type has a higher likelihood of correctly assessing the state of the economy than a dumb type.

${ }^{8}$ In section 7.3 , we study the situation in which members know their abilities.

${ }^{9}$ In section 7.2 , we discuss the situation in which $\mu$ is observed.
} 
$X=1$. We assume that messages are sent simultaneously, and that votes are cast simultaneously. ${ }^{10}$ We assume a voting rule, $f$, stipulating that $X=1$ requires that the number of favourable votes is at least $f$.

From the public's perspective, it is best if members share their private information in the communication stage, $m_{i}=s_{i}$ for all $i \in I$, and next decide to implement the project if the number of positive signals, denoted by $k$, is sufficiently large. Let $\mathrm{E}(\mu \mid k)$ denote the expected value of $\mu$ conditional on $k$ (out of $n$ ) positive signals. Furthermore, let $\bar{k}^{F B}$ be the threshold value such that $p+\mathrm{E}(\mu \mid k)>0$ for $k \geq \bar{k}^{F B}$ and $p+\mathrm{E}(\mu \mid k)<0$ for $k<\bar{k}^{F B}$.

Definition 1. The first-best decision rule consists of two parts. First, information is shared, $m_{i}=s_{i}$ for all $i \in I$. Second, the project is implemented if and only if $k \geq \bar{k}^{F B}$.

To ensure that the committee operates in an interesting environment, we assume that $p+\mathrm{E}(\mu \mid n)>0$ holds, as otherwise implementation would never be in the public's interest. The determination of $\bar{k}^{F B}$ is a statistical matter. As $p<0$, the optimal decision rule is characterized by $\bar{k}^{F B} \geq(n+1) / 2$. The stronger is the bias against project implementation, the higher is $\bar{k}^{F B}$.

\section{Transparency}

We start by analysing a transparent decision-making process. In such a process, the public observes how a decision is arrived at: it observes $m_{i}$ and $v_{i}$ of each member. We first show that such a process guarantees the implementation of the first-best decision rule and full accountability. The public's demand for transparency is therefore understandable. We then argue that because of transparency, committee members feel exposed as their reputation may get hurt. As a consequence, members would like to circumvent transparency.

To see that transparency guarantees accountability it suffices to show that members share their information in the meeting. In the absence of information on $\mu$, an assessment of a member's ability can best be based on the degree of concurrence of

\footnotetext{
${ }^{10}$ A motivation for the assumption that messages are sent simultaneously is that members prepare their analyses or statements before the meeting.
} 
individual statements. After all, if members share their information in the meeting, then the messages presented by smart members coincide, and conflicting statements are a clear indication that at least one member is dumb. The larger is the number of messages that corresponds with member $i$ 's message, the stronger is member $i$ 's reputation. As a result, if other members share their private information, then a member maximizes his expected reputation by also sharing his private information. This maximizes the likelihood that his statement equals those of a majority of fellow members.

Once members have shared information, a member's reputation is fixed. It is then in every member's interest to stick to the second part of the first-best decision rule, and to implement the project only if the number of positive messages exceeds $\bar{k}^{F B}$. As all agree and vote in the same way, the voting rule is immaterial.

Proposition 1 Suppose committee decision-making is transparent. Then, in equilibrium the committee implements the first-best decision rule. The voting rule is immaterial.

Proposition 1 suggests that transparency is in the public's interest. It serves the twin goals of guaranteeing accountability and quality decisions. However, a caveat is in order. As the public bases its assessment of a member's ability on the degree of concurrence, each member's reputation is hurt by the absence of a united front. The anticipation of possible reputational damage may induce a member to find out what other members intend to say. In fact, members seem to have a mutual interest in sharing information away from the public's eye, in a pre-meeting before the formal, 'transparent' meeting. Given that reputation depends on the degree of concurrence among members, every member would benefit from secretly meeting before the formal meeting, determine what decision on the project is first-best, and then show a united front supporting that decision in the formal meeting.

\section{$5 \quad$ Pre-meeting Deals}

A pre-meeting results in a deal concerning how to act and what to "decide" in the formal meeting. We remain agnostic about the way in which members come to such a deal. We do not assign "bargaining weights" to each member, nor do we specify 
the procedures used to reach the deal. Part of the deal is for all members to support wholeheartedly the decision, both verbally and in voting, in the formal meeting. This united front is a major obstacle to accountability, but the goal of quality decision-making is not necessarily lost. We define a Distortion-Free Pre-Meeting as follows.

Definition 1 In a Distortion-Free Pre-Meeting (DFPM) with $\mu$ unobserved, each member $i \in I$ shares his signal $s_{i}$ in the pre-meeting, and reports $m_{i}$ and votes $v_{i}$ in the formal meeting using the following strategy:

$$
\begin{cases}m_{i}=m^{g} \text { and } v_{i}=v^{g}, & \text { if }\left|s^{g}\right| \geq k^{F B} \\ m_{i}=m^{b} \text { and } v_{i}=v^{b}, & \text { if }\left|s^{g}\right|<k^{F B}\end{cases}
$$

A DFPM is a face-saving device in which members share information in private, but the decision reached is no different from what is best for the public. Members want to speak with one voice: disagreement signals lack of ability as competent members view the consequences of the project in the same way. That is, members collectively wish to make the same statement in public. Anybody deviating would hurt the reputation of everybody. Let $m_{I}^{x}$ denote that all members $i \in I$ report $m^{x}, x \in\{g, b\}$, and similarly for $v_{I}^{x}$. Thus, in case of a DFPM, the public observes either $\left(m_{I}^{g}, v_{I}^{g}\right)$ or $\left(m_{I}^{b}, v_{I}^{b}\right)$. On the basis of the DFPM strategy, the public reaches a conclusion about a member's reputation, $\widehat{\pi}\left(m_{I}^{g}, v_{I}^{g}, \bar{k}^{F B}\right)$ and $\widehat{\pi}\left(m_{I}^{b}, v_{I}^{b}, \bar{k}^{F B}\right)$. Of course, the public sees through the members' wish to be considered competent. It therefore realises that $m_{I}^{g}$ does not mean that all members held positive views, but merely that this number was large enough to warrant project implementation, $k \geq \bar{k}^{F B}$. Because $\bar{k}^{F B} \geq(n+1) / 2$, favouring project implementation commands a higher reputation than favouring the status quo as the average degree of signal concurrence is higher in the former than in the latter case. To see this, suppose $\bar{k}^{F B}=n$. In case of a DFPM, the public observes $m_{I}^{g}$ only if the degree of concurrence is maximal. This boosts each member's reputation. Collectively favouring the status quo may mean all agreed the outlook was negative, $k=0$ - again, the maximum degree of concurrence. However, it may also mean that members held differing opinions to varying degrees, $0<k<n$, a sign that some, or all, are incompetent. This dilutes the reputation of a member. 
When would a member $i$ wish to deviate from a DFPM? As a DFPM guarantees the highest expected project payoff, deviating from the DFPM must be with a view to commanding a better reputation at the inevitable cost of project payoff. With $\widehat{\pi}\left(m_{I}^{g}, v_{I}^{g}, \bar{k}^{F B}\right)>\widehat{\pi}\left(m_{I}^{b}, v_{I}^{b}, \bar{k}^{F B}\right)$, the temptation to deviate is felt most strongly if the number of positive private views falls just short of warranting project implementation, $k=\bar{k}^{F B}-1$. In this case, the costs from deviating in terms of expected project loss are the smallest, $p+\mathrm{E}\left[\mu \mid \bar{k}^{F B}-1\right]$. The gains in terms of reputation for member $i$ are $\lambda_{i}\left(\widehat{\pi}\left(m_{I}^{g}, v_{I}^{g}, \bar{k}^{F B}\right)-\widehat{\pi}\left(m_{I}^{b}, v_{I}^{b}, \bar{k}^{F B}\right)\right)$. So, for

$$
\lambda_{i} \leq \bar{\lambda}:=-\frac{p+\mathrm{E}\left[\mu \mid \bar{k}^{F B}-1\right]}{\widehat{\pi}\left(m_{I}^{g}, v_{I}^{g}, \bar{k}^{F B}\right)-\widehat{\pi}\left(m_{I}^{b}, v_{I}^{b}, \bar{k}^{F B}\right)},
$$

member $i$ does not want to deviate from the DFPM. Hence, if $\lambda_{n} \leq \bar{\lambda}$, no member wants to deviate from a DFPM. As soon as $\lambda_{n}>\bar{\lambda}$, there is room for conflict about the decision to be supported in the formal meeting.

As said, we do not intend to describe the process in the pre-meeting. Rather, we limit ourselves to describing equilibrium deals. An equilibrium deal satisfies two conditions. It satisfies the feasibility condition. The pre-meeting as a whole cannot be more inclined to favour the decision to implement than its most ardent defender, nor can it be less inclined to support that decision than its most hesitant member. It should also satisfy the endorsement condition: the deal should be endorsed in the formal meeting. Any room the latter meeting offers to deviate from the deal struck in the pre-meeting may be exploited by a member or group of members who feels cajoled into that deal.

We start the analysis by limiting attention to situations in which all $n$ members want to participate in the pre-meeting. The anticipation of an unwelcome decision may lead a member to shun the pre-meeting, and to show up at the formal meeting only. In section 7.1 , we discuss the efficacy of skipping the pre-meeting and the associated costs.

Any deal is characterized by a pair $(\bar{k}, \gamma)$, where $\bar{k}$ is a threshold value and $\gamma$ a probability. If the number of positive signals $k$ exceeds $\bar{k}$, the deal is to show a united front in favour of implementation in the formal meeting, both in the message stage and in the voting stage. If $k=\bar{k}$, then implementation is favoured with probability 
$\gamma \in(0,1]$, whereas if $k$ falls short of $\bar{k}$, the deal is to favour the status quo.

To determine the set $D_{F}$ of feasible deals, we establish its bounds. The concept of a dictator proves useful. Member $j$ is said to be a dictator if he can set the terms of the deal to maximize his own utility, unencumbered by the conditions of participation and endorsement.

Proposition 2 Suppose that $j$ is a dictator. His optimal deal $\left(\bar{k}_{j}, \gamma_{j}\right)$ is as characterized as follows.

(i) If he cares little about his reputation, $\lambda_{j} \leq \bar{\lambda}$, the optimal deal is characterized by $\left(\bar{k}^{F B}, 0\right)$.

(ii) If $\lambda_{j}>\bar{\lambda}$, then one of the following holds.

(ii-a) [pure strategy optimal deal] Member $j$ dictates all members to favour implementation if $k \geq \bar{k}_{j}$, and to favour the status quo for $k<\bar{k}_{j}$, where $\bar{k}_{j}$ satisfies

$$
\begin{aligned}
p+\mathrm{E}\left[\mu \mid \bar{k}_{j}\right]+\lambda_{j} \widehat{\pi}\left(m_{I}^{g}, v_{I}^{g}, \bar{k}_{j}\right) & >\lambda_{j} \widehat{\pi}\left(m_{I}^{b}, v_{I}^{b}, \bar{k}_{j}\right) \\
p+\mathrm{E}\left[\mu \mid \bar{k}_{j}-1\right]+\lambda_{j} \widehat{\pi}\left(m_{I}^{g}, v_{I}^{g}, \bar{k}_{j}\right) & <\lambda_{j} \widehat{\pi}\left(m_{I}^{b}, v_{I}^{b}, \bar{k}_{j}\right) .
\end{aligned}
$$

(ii-b) [mixed strategy optimal deal] Member $j$ dictates all members to favour implementation if $k>\bar{k}_{j}$ with probability one, to favour implementation if $k=\bar{k}_{j}$ with probability $\gamma_{j}$, and to favour the status quo for $k<\bar{k}_{j}$, where $\left(\bar{k}_{j}, \gamma_{j}\right)$ satisfies

$$
p+\mathrm{E}\left[\mu \mid \bar{k}_{j}\right]+\lambda_{j} \widehat{\pi}\left(m_{I}^{g}, v_{I}^{g}, \bar{k}_{j}, \gamma_{j}\right)=\lambda_{j} \widehat{\pi}\left(m_{I}^{b}, v_{I}^{b}, \bar{k}_{j}, \gamma_{j}\right)
$$

To understand why there are two types of optimal deals in case of $\lambda_{j}>\bar{\lambda}$, note that (6) says that for given posterior beliefs $\widehat{\pi}\left(m_{I}^{g}, v_{I}^{g}, \bar{k}_{j}\right)$ and $\widehat{\pi}\left(m_{I}^{b}, v_{I}^{b}, \bar{k}_{j}\right)$ consistent with $\bar{k}_{j}$, member $j$ does not want to dictate project implementation in case the number of positive assessments equals $\bar{k}_{j}-1$. He therefore does not mix in case of $k=\bar{k}_{j}-1$. In case (ii-b), the situation is different. Now for given beliefs that are consistent with implementation with probability one for $k \geq \bar{k}_{j}$, member $j$ would like to implement for $k=\bar{k}_{j}-1$. But if the posterior beliefs were based on the committee implementing with probability one for $k \geq \bar{k}_{j}-1$, then he would like to refrain from implementing if $k=\bar{k}_{j}-1$. As a result, there is a probability $\gamma_{j}$ with which the project is implemented in case of $k=\bar{k}_{j}$, with $\left(\bar{k}_{j}, \gamma_{j}\right)$ characterized by $(7)$. 
Strong reputational concerns, $\lambda_{j}>\bar{\lambda}$, lead member $j$ to prefer deviations from the DFPM. The stronger these concerns are, the larger the deviation becomes. There is a limit, though, to the extent to which member $j$ prefers deviating from the DFPM. The deviation is driven by the value attached to the 'reputational gap', the difference in reputation commanded in case of favouring implementation on the one hand and supporting the status quo on the other. This can most easily be seen by rewriting (7):

$$
\lambda_{j}(\underbrace{\widehat{\pi}\left(m_{I}^{g}, v_{I}^{g}, \bar{k}_{j}, \gamma_{j}\right)-\widehat{\pi}\left(m_{I}^{b}, v_{I}^{b}, \bar{k}_{j}, \gamma_{j}\right)}_{\text {reputational gap }})=-\left(p+\mathrm{E}\left[\mu \mid \bar{k}_{j}\right]\right)
$$

Recall that with $\bar{k}^{F B}>(n+1) / 2$, the reputational gap exists because the average degree of signal concurrence in case of implementation is higher than in case of maintaining the status quo. In equilibrium, the higher is the value of $\lambda_{j}$, the larger is the deviation from the DFPM, the lower is the average degree of signal concurrence in case of implementation, and the larger it is in case of maintaining the status quo. As a result, the equilibrium reputational gap becomes smaller with an increase in $\lambda_{j}$. It would disappear if member $j$ were to dictate implementation as often as the status quo. Given that in equilibrium the reputational gap is needed to compensate for the loss in project value, member $j$ stops well short of a situation in which the gap would vanish.

Proposition 2 specifies the pairs $\left(\bar{k}_{n}, \gamma_{n}\right)$ and $\left(\bar{k}_{1}, \gamma_{1}\right)$ that set the bounds for the set of feasible deals $D_{F} \cdot{ }^{11}$ Of course, $\bar{k}_{n} \leq \bar{k}_{1}$. We do not impose that a feasible deal is the optimal deal of some member $j$. Any feasible deal will satisfy two conditions. First, implementation commands a higher reputation than maintaining the status quo. Second, if there is a distortion, it is in the direction of unwarranted implementation. In what follows, we limit analysis to deals in $D_{F}$. Given a feasible deal, what conditions should hold for the deal to be endorsed in the formal meeting?

\subsection{Endorsement}

We say that a deal is endorsed in the formal meeting if no individual member or coalition of members has an incentive to deviate in the formal meeting, for any number of favourable signals $k$. Two members are potentially most inclined to

${ }^{11}$ Formally, $D_{F}=\left\{(\bar{k}, \gamma) \mid \bar{k} \in\left\{\bar{k}_{n}, \ldots, \bar{k}_{1}\right\}, \gamma \in[0,1]\right\} \backslash\left\{\left\{\left(\bar{k}_{n}, \gamma\right) \mid \gamma>\gamma_{n}\right\} \cup\left\{\left(\bar{k}_{1}, \gamma\right) \mid \gamma<\gamma_{1}\right\}\right\}$. 
obstruct a deal, member $n$ who values his reputation more than anybody else, and member 1 who cares the least about his reputation. Member $n$ is most likely to be dissatisfied with a deal to maintain the status quo, as he is most attracted by the higher reputation commanded by project implementation. Member 1 might want to oppose a deal to favour implementation if the higher reputation this decision commands does not outweigh the loss in project payoff. If neither member 1 nor $n$ wants to oppose a deal, then all members endorse it. A member considering obstructing the deal asks himself two questions: will I be successful, and how much does obstruction cost me? Stopping a pre-cooked decision requires breaking the united front. This inevitably implies a loss of reputation. Clearly, then, a deal favouring the status quo will never be opposed as the gains hoped for cannot be realized. Member 1, however, might be willing to accept the low reputation that comes with a broken front. A necessary condition is that his deviation guarantees that the deal to implement is turned into support for the status quo in the formal meeting.

One part of an equilibrium deal is the formation of a united front. As a result, in equilibrium the public observes either $\left(m_{I}^{g}, v_{I}^{g}\right)$ or $\left(m_{I}^{b}, v_{I}^{b}\right)$. Deviations from equilibrium deals give rise to out-of-equilibrium beliefs as to the members' reputations. To study deviations from equilibria, we have to make assumptions on those beliefs. Throughout, out-of-equilibrium beliefs are based on two premises.

Premise 1. A deviation by member $i$ does not provide direct information on $s_{i}$, but provides information on $k$.

This is plausible, as $i$ has participated in the pre-meeting and knows $k$.

Premise 2. The public tries to infer information on the degree of signal concurrence from the deviation and any actions that members take next. A higher degree of inferred signal concurrence improves members' reputations.

Together both premises have the following implications. First, a deviation by member $i$ shows that a deal conflicts with member $i$ 's interests. Second, breaking a united front hurts the reputation of everybody as it signals lack of concurrence. 
Third, from a deviation followed by (voting behaviour such that) $X=1$ the public infers a higher value of $k$ than from a deviation followed by $X=0$. The reason is that the lower is the value of $k$, the smaller is the expected value of the project. Below some critical value, the committee chooses to maintain the status quo. To understand why this hurts reputation, observe that the lack of signal concurrence is maximal if there are as many positive as negative signals, $k=(n+1) / 2$. The less evidence $k$ there is, the more this situation is approached, and the worse it is for reputation. Finally, the more members deviate from a united front, the lower the reputation of every member, deviating or not, will be. The reason is that the more members deviate, the larger is the highest degree $\lambda_{i}$ to which a deviating member cares about his reputation, and thus the less positive evidence $k$ must have been presented in the pre-meeting.

\subsubsection{Endorsement in the Voting Stage}

To analyse endorsement in the voting stage, assume that endorsement of the deal in the communication stage is unproblematic. In the absence of the possibility of forming coalitions, the voting stage offers little room for an individual member to stop the project from being implemented. First, it requires unanimity, $f=n$.

Second, it hurts reputation. Let $\widehat{\pi}_{i}\left(m_{I}^{g}, v_{I \backslash i}^{g}\right)$ denote the out-of-equilibrium belief the public holds if it were to observe that member $i$ breaks the united front in the voting stage. The incentive to vote against implementation is felt most strongly in case of $k=\bar{k}$. The member most inclined to block implementation is member 1 .

Proposition 3 Suppose coalitions cannot be formed. The deal will be endorsed in the voting stage in the absence of unanimity voting. In case of unanimity, it will be endorsed if

$$
p+\mathrm{E}[\mu \mid \bar{k}]+\lambda_{1} \widehat{\pi}\left(m_{I}^{g}, v_{I}^{g}, \bar{k}, \gamma\right)<\lambda_{1} \widehat{\pi}_{i}\left(m_{I}^{g}, v_{I \backslash i}^{g}, v_{i}^{b}\right)
$$

\subsubsection{Endorsement in the Communication Stage}

The main advantage that deviating in the communication stage has over deviating in the voting stage is that an individual deviation in the former stage can act as a lever to induce widespread defection from the deal in the latter stage. This is particularly 
useful if a single member cannot veto project implementation and a coalition cannot be formed. For the deal to be endorsed in the communication stage, then, either no individual is willing to break the united front in that stage, or the leverage of his deviant behaviour is too small. It is too small, if the decisive member $d=n+1-f$ continues voting favourably. ${ }^{12}$

To derive the condition that must hold for the deviation in the communication stage to have too little leverage, assume that member 1 broke the united front in the communication stage. This can be written as $m_{I \backslash 1}^{g}$. After this exchange, committee members face a new situation. Independent of the decision that is taken next on the project, the reputation of each member has been damaged relative to what it would have been had the deal to support implementation been endorsed. This is so, because $\hat{\pi}\left(m_{I}^{g}, v_{I}^{g}, \bar{k}, \gamma\right)$ is based on the possibility that signal concurrence was high, with at least $k \geq \bar{k}^{F B}$ equal, positive signals. After the deviation, the public knows that such can no longer be the case. All but member 1 may want to keep up appearances by voting favourably.

As was already derived from the two premises concerning out-of-equilibrium beliefs, implementation commands a higher out-of-equilibrium reputation than the status quo. Moreover, for a given decision $X$, reputation will not depend on the actual distribution of votes. If it would, members could costlessly, i.e., without affecting the decision on the project, improve their reputations. The public would see through this cheap talk behaviour. The out-of-equilibrium belief does depend on the decision on the project, $X$. A change in decision affects project payoffs, a costly signal. Therefore, $\hat{\pi}\left(m_{I \backslash 1}^{g}, X=1\right)>\hat{\pi}\left(m_{I \backslash 1}^{g}, X=0\right)$. Note that these beliefs are independent of the identity of the member, as they are based on values of $k$.

We are now ready to state the conditions that should hold for the deal to be endorsed. The defection from the united front by member 1 in the communication stage remains unsuccessful if member $d$ still prefers implementation over status quo. But even if member $d$ is willing to maintain the status quo if member 1 were to deviate, it could be that member 1 finds it prohibitively costly to take this route to oppose the deal.

\footnotetext{
${ }^{12}$ If he votes favourably, so do all members $i>d$ who are more willing to give up project value for a strengthened reputation. As a result, the project is implemented. If he votes against, so do all members $i<d$ who care less about their reputation, implying that the required majority is not attained and the status quo is maintained.
} 
Proposition 4 Stopping a deal requires both that a member breaks the united front in the deliberation stage, and that this deviation triggers the decisive member $d$ to support the status quo in the voting stage. Endorsement is guaranteed (i) if member $d$ continues to vote for implementation if member 1 were to break the united front in the deliberation stage,

$$
p+E[\mu \mid \bar{k}]+\lambda_{d} \hat{\pi}\left(m_{I \backslash 1}^{g}, X=1\right) \geq \lambda_{d} \hat{\pi}\left(m_{I \backslash 1}^{g}, X=0\right),
$$

or (ii) if member 1 does not want to break the united front in the deliberation stage although member $d$ would then decide to maintain the status quo,

$$
p+E[\mu \mid \bar{k}]+\lambda_{1} \hat{\pi}\left(m_{I}^{g}, v_{I}^{g}, \bar{k}, \gamma\right) \geq \lambda_{1} \hat{\pi}\left(m_{I \backslash 1}^{g}, X=0\right) .
$$

\subsection{A note on equilibria}

We conclude this section with a note on equilibria. The situation we describe is a voting game preceded by communication. Many uninteresting equilibria exist in such games. For example, in our game it is an equilibrium for each member to vote against implementation in the formal meeting irrespective of his signal. With this kind of voting behaviour, no deal to support project implementation will be endorsed. We ignore this kind of uninteresting equilibria. Moreover, the focus of our analysis is on deals that unanimously support the decision on the project. Of course, other forms of support can be imagined. A somewhat plausible one is that when $k<\bar{k}^{F B}$ the committee wants to convince the public that $k$ only just fell short of $\bar{k}^{F B}$ (to keep the public from thinking disagreement was widespread). It could do so by consciously presenting a small lack of disagreement by, say, stating $m_{I / 1}^{g}$ and voting $v_{I}^{b}$ in the formal meeting. As there are no costs attached to such faking, it is cheap talk. In equilibrium, the public sees through this behaviour. ${ }^{13}$

\subsection{Coalition deviations possible}

The voting stage offers little room to block implementation if a member can only consider a unilateral deviation. We now assume that members can find out whether

\footnotetext{
${ }^{13}$ We have also ignored babbling equilibria and equilibria with a non-natural language.
} 
other members are disenchanted with the result of the pre-meeting. For example, while leaving the pre-meeting, it may be quite clear who is happy with the deal and who is not. This creates more room for successful deviations. If implementation requires $f$ favourable votes, a coalition $C$ including the decisive member $d=n+1-f$ can successfully block it. There is however one major obstacle to forming such a coalition, as plausible out-of-equilibrium beliefs are decreasing in the size of the coalition breaking the united front. Therefore, if member 1 on his own is not willing to break the united front, the formation of a coalition does not help. A larger coalition can only help to overcome lack of numbers, but does so by compromising every members' reputation. The project is endorsed if member $d$ is unwilling to be part of a coalition breaking the united front.

Proposition 5 Suppose that coalitions can be formed, and that the voting rule is characterized by $f$. The deal will be endorsed in the voting stage if member $d=$ $n+1-f$ is unwilling to be part of a coalition that breaks the united front,

$$
p+\mathrm{E}[\mu \mid \bar{k}]+\lambda_{d} \widehat{\pi}\left(m_{I}^{g}, v_{I}^{g}, \bar{k}, \gamma\right) \geq \lambda_{d} \widehat{\pi}_{d}\left(m_{I}^{g}, v_{I \backslash C}^{g}\right)
$$

where $C=\{1, \ldots, d\}$.

\subsection{When is the temptation to deviate strongest?}

The fact that committee members must endorse a deal both in the communication stage and voting stage of the formal meeting raises the question which of the two stages sets the most restrictive limit to deals struck in the pre-meeting. We show that the opportunity members have to state in public that a project is undesirable imposes a more restrictive limit to deals than the opportunity to block an undesirable project in the voting stage. This can be seen by comparing the inequalities in Propositions 4 and 5. Essential are the out-of-equilibrium posterior probabilities. As discussed earlier, our assumptions on those probabilities are based on the idea that the public tries to form a view on the degree of signal concurrence. The right-hand sides of (9), (10) and (11) all pertain to situations where $k$ is such that member $d$ is

willing to block implementation. So it is natural to assume that $\hat{\pi}\left(m_{I \backslash 1}^{g}, X=0\right)=$ $\hat{\pi}\left(m_{I}^{g}, v_{I \backslash C}^{g}\right)$. Under this assumption, (10) is more restrictive than (11) as $\lambda_{1}<\lambda_{d}$. 
Moreover, (9) is also more restrictive than (11). The reason is that when member 1 has deviated in the communication stage, the public knows that $k<\bar{k}^{F B}$. Hence, even if the committee were next to implement the project, each member's reputation (including member $d$ 's) would be lower than in case the united front was upheld, $\hat{\pi}\left(m_{I \backslash 1}^{g}, X=1\right)<\widehat{\pi}\left(m_{I}^{g}, v_{I}^{g}, \bar{k}, \gamma\right)$. As a result, once member 1 has deviated in the communication, the drop in reputation for member $d$ that stems from following 1's lead rather than keeping up appearances is smaller. Member $d$ therefore wants to support member 1 who deviated in the communicated stage for a lower $k$ than he wants to participate in a coalition stopping implementation in the voting stage.

\section{Is transparency to no avail?}

We have argued that transparency may prompt committee members to organize premeetings so as to pre-cook decisions. Does this mean that reforms that are intended to foster transparency are to no avail? To answer this question we compare the outcomes under a closed decision-making process (CDP) and the outcomes under a 'transparent' process with pre-meetings (TPM).

In a CDP, deliberation and voting take place behind closed doors. As a result, the public observes the ultimate decision, but does not observe how it is reached. Visser and Swank (2007) show that in such an environment, member $d=n+1-f$ is decisive. More specifically, in case of a CDP the decision on $X$ can be characterized by (6) and (7), or (8), with $j=d$. This immediately brings us to the first difference between the two types of decision-making processes. In a CDP, the maximum distortion is known and depends on $\lambda_{d}$. In a TPM, the distortion is less predictable. The reason is that in the pre-meeting a formal voting rule does not exist. As a result, the distortion may be smaller in case members $i<d$ gain the upper hand; but it could also be larger if some member $i>d$ puts his mark on the deal. We regard this unpredictability as a drawback of a TPM.

Let us now investigate whether distortions that are possible under CDP are also possible under TPM. To this end, we assume that the decisive member of the formal meeting, $d$, is also the member who dictates the deal in the pre-meeting. Will a TPM perform as a CDP? That is, can the dictator have his way? In section 5.1, we stressed that the endorsement condition reins in the extent to which deals can be 
distortive. From a social point of view, a TPM yields better outcomes than a CDP, if distorted decisions implied by (8) are not endorsed in the formal meeting. This requires at least that $\lambda_{1}$ is sufficiently small such that member 1 is willing to state his opposition to project implementation in the communication stage. But it also requires that next member $d$ is willing to vote against implementation. This means that (7) should hold, with $j=d$, as this characterizes the decision in the CDP. But (10) should be violated, such that once member 1 has broken the united front, member $d$ no longer wants to support his own deal in the 'transparent' part of the TPM. A sufficient condition is that $\hat{\pi}\left(m_{I}^{b}, v_{I}^{b}, \bar{k}_{d}, \gamma_{d}\right)<\hat{\pi}\left(m_{I \backslash 1}^{g}, X=0\right) \cdot{ }^{14}$ The public

deduces from the observation of $m_{I \backslash 1}^{g}$ that $k \in\left\{\bar{k}_{d}, \ldots, \bar{k}^{F B}-1\right\}$, and from the decision to maintain the status quo once the united has been broken that the actual value of $k$ is lower than some $\hat{k}$, with $\bar{k}_{d}<\hat{k} \leq \bar{k}^{F B}-1$. Although this hurts a member's reputation when compared with the reputation commanded by a united front supporting implementation, it may still be better than the reputation commanded by a united front supporting the status quo. This is the case if $\bar{k}_{d}$ is relatively high such that the public concludes from observing $\left(m_{I \backslash 1}^{g}, X=0\right)$ that the degree of signal concurrence was relatively high. ${ }^{15}$ The above example illustrates that reforms making decision-making processes more transparent may matter. Decision-making under TPM is possibly less distortionary than decision-making under CDP.

\section{Extensions}

\subsection{Participation in the pre-meeting}

So far we have assumed that all members attend the pre-meeting. In this subsection we argue that the incentive for an individual member to stay away from a premeeting is weak. The primary reason why a member would want to skip a premeeting is to reduce the likelihood that the decision on the project deviates from

\footnotetext{
${ }^{14}$ Note that the expression on the right hand side of (7) is larger than the expression on the right hand side of $(9)$ as $\hat{\pi}\left(m_{I}^{g}, v_{I}^{g}, \bar{k}_{d}, \gamma_{d}\right)>\hat{\pi}_{d}\left(m_{I \backslash 1}^{g}, X=1\right)$.

${ }^{15}$ An extreme example illustrates. Take $n=100, \bar{k}^{F B}=100$, and $\bar{k}_{d}=96$. Observing $\left(m_{I}^{b}, v_{I}^{b}\right)$ implies $k<96$. This gives very little information on members' abilities, and allows for very low degrees of signal concurrence. But $\left(m_{I \backslash 1}^{g}, X=0\right)$ means that $k$ equals at least 96 , and therefore virtually full signal concurrence.
} 
the one he deems best. The cost of staying away from a pre-meeting is a fall in reputation because the united front is possibly broken. Therefore, the analysis of the participation decision revolves around the trade-off between a less distorted implementation decision on the one hand, and a drop in reputation on the other. Clearly, member 1 has the strongest incentive to stay away from the pre-meeting. We therefore focus on him.

One important factor that reduces the attractiveness of skipping the pre-meeting is its limited efficacy. If member 1 decides to skip the pre-meeting he only knows his own private view $s_{1}$, but not $k$. Conflict of interests about the deal need not have occurred in the pre-meeting. For example, if $k>\bar{k}^{F B}$ or $k<\bar{k}$, no disagreement arises. The benefits of staying away are then zero, whereas the cost in terms of a drop in reputation may be substantial. This lack of efficacy is a drawback that breaking the united front in the formal meeting does not have as the latter decision can be conditioned on $k$.

Lack of efficacy is not the only reason why members' incentives to skip a premeeting are weak. By means of an example we show that member 1's absence may aggravate distortions. Assume that if all members participate in the pre-meeting, the deal is characterized by $(\bar{k}, \gamma)$. Suppose member 1 holds a negative view, $s_{1}^{b}$, and deviates from the equilibrium by not attending the pre-meeting. Members who do join deduce from his absence that member 1 holds a negative view. They can therefore act in full knowledge of the total number of positive signals $k$. They also anticipate that 1 will state $m_{1}^{b}$ in the formal meeting. Are they still indifferent between $X=1$ and $X=0$ for $k=\bar{k}$ ? A deal to support the status quo continues to yield $\hat{\pi}\left(m_{I}^{b}, v_{I}^{b}\right)$, as the public still perceives a united front. A deal to support project implementation now yields $p+\mathrm{E}[\mu \mid \bar{k}]+\lambda \hat{\pi}_{i}\left(m_{I \backslash 1}^{g}, v_{I \backslash 1}^{g}\right)$. The out-of-equilibrium belief of the public $\hat{\pi}_{i}\left(m_{I \backslash 1}^{g}, v_{I \backslash 1}^{g}\right)$ is based on the assumption that 1 did not attend the pre-meeting. This belief seems the most plausible one when focusing on a member's decision whether to skip the pre-meeting. The fact that member 1 is now identified with a minority signal hurts his reputation considerably, and further reduces the attractiveness of staying away from the pre-meeting. It also implies that the members who do attend the pre-meeting may command a higher reputation. On the one hand, the public realises that $m_{I \backslash 1}^{g}$ implies $k \neq n$. This reduces their reputation, and makes it less attractive to have a deal that favours implementation 
in case of $k=\bar{k}$. On the other hand, as 1 is identified to be a member who held a negative view, the likelihood that any of the members who joined the pre-meeting held that minority view has gone down. This, in turn, strengthens their reputation and makes them more inclined to distort the decision. If the latter effect is stronger than the former, staying away from the pre-meeting effectively backfires on member $1 .^{16}$

\subsection{Consequences of final decision become observable}

In this section we assume that the state of the environment becomes observable. This information can help in assessing a member's reputation. In the literature on reputational concerns, this assumption is sometimes made, see e.g. Ottaviani and Sørensen (2001) and Levy (2007). We show first of all that the public's demand for transparency can again be understood. Next, thanks to the observability of $\mu$, the goal of a pre-meeting changes. With $\mu$ observable, a member's reputation is strengthened if he correctly forecasts the state of the environment. A pre-meeting helps in improving the quality of the forecast by basing it on additional information. Finally, we emphasize that not all members may want to deviate from a transparent meeting by gathering secretly before a formal meeting. As a result, real transparency without a pre-meeting can be an equilibrium.

If a member shares his private information in a transparent meeting, his reputation depends exclusively on the quality of the match between his private statement and the observed state of the economy. We write $\hat{\pi}_{i}\left(m_{i}, \mu\right):{ }^{17}$

$$
\hat{\pi}_{i}\left(m_{i}^{g}, \mu=h\right)=\hat{\pi}_{i}\left(m_{i}^{b}, \mu=-h\right)>\hat{\pi}_{i}\left(m_{i}^{b}, \mu=h\right)=\hat{\pi}_{i}\left(m_{i}^{g}, \mu=-h\right)=0 .
$$

\footnotetext{
${ }^{16}$ Such is the case for a committee with, e.g., $n=5, k^{F B}=5,(\bar{k}, \gamma)=(4,0)$, and a value of $\pi$ that is not too high. If everybody joins the pre-meeting, $m_{I}^{g}$ may mean $k=5$, which commands a very high reputation. For $\pi$ not too high, it is however much more likely to mean $k=4$. Conditional on $k=4$, the likelihood that, say, member 2 is the outlier $\left(s_{2}=s^{b}\right.$ and $\left.s_{1}=s_{3}=s_{4}=s_{5}=s^{g}\right)$ is $1 / 5$. Being an outlier hurts one's reputation considerably. Now suppose instead that 1 does not join the pre-meeting, and that those who continue using $(\bar{k}, \gamma)=(4,0)$ to strike a deal. If the public observes $m_{I \backslash 1}^{g}$, it then follows that $k=4$ (rather than $k \in\{4,5\}$ ) and that 2 is not an outlier. As a result, for not too high values of $\pi$, the reputation of member 2 is higher in case 1 does not join the pre-meeting than if he does.

${ }^{17}$ Note that $\operatorname{Pr}\left(m_{i}^{g}, \mu=h \mid t_{i}=s m\right)=1 / 2, \quad \operatorname{Pr}\left(m_{i}^{g}, \mu=h \mid t_{i}=d u\right)=1 / 4, \quad$ and $\operatorname{Pr}\left(m_{i}^{g}, \mu=-h \mid t_{i}=s m\right)=0$. Using Bayes rule, one obtains $\hat{\pi}_{i}\left(m_{i}^{g}, \mu=h\right)=2 \pi /(1+\pi)$ and $\hat{\pi}_{i}\left(m_{i}^{g}, \mu=-h\right)=0$.
} 
Because a member is competent with positive probability, it is more likely that his private view corresponds with the state of nature than that it does not. This implies that for a given view, and with beliefs as in (12), a member maximizes his expected reputation by sharing his information. As the decision on the project does not affect a member's reputation, there is no reason to distort that decision. Again, the public's demand for transparency can be understood.

The anticipation of possible reputational damage may induce a member to collect additional information before making a statement in public. Suppose members deviate from the transparent meeting by gathering in advance, and sharing their private views. If a majority of members holds positive views, $k>(n+1) / 2$, a positive state of the economy is more likely than a negative. As a result, for given ex post beliefs (12) and speaking from a reputational perspective only, it is then in every member's interest to report $m_{i}^{g}$ in the formal meeting. That is, the purpose of a pre-meeting is not to feign concurrence, but for every individual member to improve the accuracy of his own public statement.

In case the state of the environment remains unobserved, transparency is hard to sustain as all members agree that a specific deviation is best: gather before the formal meeting to exchange private views, decide what decision is first-best given that information, and collectively support that decision in the formal meeting. This deviation yields the highest project payoff and the highest reputation for all. Matters are different in case the state is observed as conflicts may arise concerning the final decision. To see this, suppose members deviate from the transparent meeting by gathering in advance, and sharing their private views. For $k \geq \bar{k}^{F B}$, all members agree that both from a reputational perspective and from a project value perspective, supporting implementation is best. Similarly, if $k<(n+1) / 2$, reputational concerns and project value concerns are perfectly aligned: all members favour the status quo. However, for $k \in\left\{(n+1) / 2, \ldots, \bar{k}^{F B}-1\right\}$, any member is on the horns of a dilemma. From a reputational perspective each member wants to favour implementation, but project value considerations dictate to maintain the status quo. Members differ in the way they evaluate these costs and benefits as they attach different weights to their reputations. The anticipation that a deviation from the transparent meeting may give rise to conflicts among members concerning the decision to support puts a brake on the formation of a pre-meeting. 
Now suppose a pre-meeting of all $n$ members does take place. Given the just mentioned difficulties in forming a pre-meeting, conflicts of interest in the pre-meeting are likely to be smaller when $\mu$ is observable than when $\mu$ is unobservable. Nevertheless, conflicts may arise for $k \in\left\{(n+1) / 2, \ldots, \bar{k}^{F B}-1\right\}$. From a reputational perspective, every member should put his money where his mouth is, and favour implementation both in the deliberation stage and in the voting stage. Doing otherwise, i.e., verbally expressing support for implementation but voting against, shows lack of conviction and costs reputation. Members who care little about their reputation may accept this lower reputation if unwarranted implementation is too costly and can be stopped in this way. The outcome of the pre-meeting is a deal. Any feasible deal is characterized by a threshold value $\hat{k}$, with $\hat{k} \geq(n+1) / 2$, such that for

$k \geq \hat{k}$, members state $m_{i}^{g}$ and vote accordingly, $v_{i}^{g}$; for $k \in\{(n+1) / 2, \ldots, \hat{k}-1\}$, members state $m_{i}^{g}$ but vote $v_{i}^{b}$; and for $k<(n+1) / 2$, each member states $m_{i}^{b}$ and votes $v_{i}^{b}{ }^{18}$ Members 1 and $d$ remain key in determining whether a feasible deal will be endorsed. As before, the scope for an individual member to prevent a distorted implementation decision in the voting stage is limited. A deviation in the deliberation stage requires that member 1 cares little about his reputation, and that member $d$ is willing to support his deviation in the voting stage. Out-of-equilibrium beliefs continue to play an important role.

\subsection{Members know their abilities}

So far, we have assumed that a committee member neither knows his own ability nor the other members' abilities. When committees regularly gather, this assumption is not plausible. It is then likely that at least some learning about abilities takes place. In this section, we consider a committee in which every member knows his own type and the other members' types. We maintain the assumption that the public only knows the prior probability that a member is smart, $\pi$. All this is common knowledge. In particular, the public knows that among committee members ability levels are known. To ensure that our model describes an interesting situation, we assume that the view of a smart member may be flawed, and the view of a dumb

\footnotetext{
${ }^{18}$ Feasible deals can also be characterized by a mixed strategy characterized by a pair $(\hat{k}, \gamma)$.
} 
member may be correct,

$$
\begin{aligned}
& 1>\operatorname{Pr}\left(\mu=h \mid s^{g}, s m\right)>\operatorname{Pr}\left(\mu=h \mid s^{g}, d u\right)>1 / 2 \text { and } \\
& 1>\operatorname{Pr}\left(\mu=-h \mid s^{b}, s m\right)>\operatorname{Pr}\left(\mu=-h \mid s^{b}, d u\right)>1 / 2 .
\end{aligned}
$$

The determination of the conditions under which implementation is first-best is a statistical matter that requires the appropriate weighing of members' views, see Nitzan and Paroush (1982). We assume again that $\mu$ is not observed by the public, and that $p<0$ is such that, if all members are smart, implementation requires at least $(n+1) / 2$ positive signals.

If a member knows his ability, he may use the transparent meeting to posture to make the public believe that he is more able than he knows he is. As a result, a transparent meeting may give rise to a distorted decision. To see this, suppose members share their views in the communication stage, and would stick to the first-best rule. As $\mu$ is not observed, the public bases a member's reputation on the degree of signal concurrence and on the decision on the project, as the decision contains information on the quality of the signals. For a given value of $k, \hat{\pi}(k, X=1)>\hat{\pi}(k, X=0)$, as on average a higher number of members is smart in case of implementation. By choosing $X=1$ rather than $X=0$, committee members may pretend that a high number of members is smart. However, deviating from the socially optimal decision requires cooperation among members or requires some norm regarding the specific conditions under which the project should be implemented. As a result, several equilibria exist. In some of them, members distort the implementation decision to feign that many members are smart. Hence, the assumption on whether or not members know their own and each others' abilities may affect members' incentives to distort the implementation decision under transparency. Members' incentives to posture may lead to incentives to distort the implementation decision.

The incentive to organize a pre-meeting does not change. As before, disagreement among committee members damages their reputations. By organizing a pre-meeting committee members can conceal disagreement. Moreover, reputational concerns may prompt committee members to make socially undesirable deals in a pre-meeting, and the formal meeting may put a limit to the extent to which such deals are distortionary. 


\section{Conclusion}

If decisions are made behind closed doors, those who have delegated decision power may suspect that the decisions made are not in their interest. Why else the secrecy? Requiring transparency is then a logical reaction. Some case studies suggest that committees shy away from deliberating in transparent meetings. The real deliberation seems to move to a pre-meeting, where a deal is reached as to the decision to be unanimously supported in the formal meeting. In this paper, we have presented a theory that explains the public's demand for transparency; the committee members' aversion to it; and the emergence of a pre-meeting. Rather than imposing structure on the decision process in the pre-meeting, we have focused on deals that 'survive' (are endorsed in) the formal meeting. Our analysis suggests that pre-meetings may partially nullify the benefits of transparency. However, the fact that members can choose to break the united front in the formal meeting or decide not to take part in the pre-meeting puts limits on distortionary deals.

As far as we know, our paper presents the first formal analysis of the emergence and consequences of pre-meetings. We are aware that our analysis should be regarded as a first step to a richer model. We have not addressed several issues that seem to be relevant for understanding the role of pre-meetings in decision-making processes. Let us briefly discuss three of them. First, in our model committee members differ in one dimension, namely in the extent to which they are concerned about their reputations. In many applications, committee members also differ in their preferences concerning the desirability of the project. Of course, introducing this aspect into our model would affect members' incentives to support a deal in the formal meeting. Second, we have assumed in this paper that in the pre-meeting committee members share information. One motivation for this assumption is that committee members are often experts in their fields. In several situations, experts may fool the public, faking a united front, but are not capable of fooling each other. However, in other situations experts may also trick each other. The analysis of committee members' incentives to share information in the pre-meeting is thus a promising next step. Third, we have limited the analysis to pre-meetings in which all members participate. By assumption, we have ruled out the possibility of the emergence of several pre-meetings. We conjecture that the emergence of several 
pre-meetings is especially likely when information in pre-meetings can be manipulated. The formation of homogenous groups may facilitate communication among members.

\section{References}

Aronson, Eliot, Timothy D. Wilson, and Robin M. Akert, 2005, Social Psychology, Pearson Prentice Hall, New Jersey: Upper Saddle River.

Austen-Smith, David and Jeffrey S. Banks, 1996, Information Aggregation, Rationality and the Condorcet Jury Theorem, American Political Science Review, 90, 43-45.

Austen-Smith, David,and Timothy Feddersen, 2002, Deliberation and Voting Rules, Northwestern University Working Paper.

Caillaud, Bernard and Jean Tirole, 2007, Consensus Building: How to Persuade a Group, IDEI working paper 435.

Coughlan, Peter J., 2000, In Defense of Unanimous Jury Verdicts: Mistrials, Communication, and Strategic Voting, American Political Science Review, 375-393.

Dessein, Wouter 2007, Why a Group Needs a Leader: Decision-Making and Debate in Committees, GSB Chicago.

Eliaz, Kfir, Debraj Ray, and Ronny Razin, 2006, A Decision-Theoretic Basis for Choice Shifts in Groups, American Economic Review, 96, 1321-1332.

Feddersen, Timothy and Wolfgang Pesendorfer, 1998, Convicting the Innocent: The Inferiority of Unanimous Jury Verdicts under Strategic Voting, American Political Science Review, 92, 23-35.

Fingleton, John and Michael Raith, 2005, Career Concerns of Bargainers, Journal of Law, Economics and Organization, 21, 179-204.

Geraats, Petra M., 2002, Central Bank Transparency, Economic Journal, 112, 532565.

Gerardi, Dino and Leeat Yariv, 2006, Deliberative Voting, Journal of Economic Theory, 134, 317-338. 
Gersbach, Hans and Volker Hahn, 2004, Voting Transparency, Conflicting Interests and the Appointment of Central Bankers, Economics and Politics, 16, 321-345.

Janis Irving L., 1972, Victims of Groupthink: A Psychological Study of ForeignPolicy Decisions and Fiascoes, Houghton Mifflin Company, Boston.

Kramer, R., 1998, Revisiting the Bay of Pigs and Vietnam Decisions 25 Years Later: How Well Has the Groupthink Hypothesis Stood the Test of Time?, Organizational Behavior and Human Decision Processes, 73, 236-271.

Ladha, Krishna K., 1992, The Condorcet Jury Theorem, Free Speech, and Correlated Votes, American Journal of Political Science, 36, 617-634.

Levy, Gilat, 2007, Decision Making in Committees: Transparency, Reputation and Voting Rules, American Economic Review, 97, 150-168.

Li, Hao, Sherwin Rosen and Wing Suen, 2001, Conflict and Common Interests in Committees, American Economic Review, 91, 1478-1497.

Mattozzi, Andrea and Antonio Merlo, 2007, The Transparency of Politics and the Quality of Politicians, American Economic Review, 97, 311-315.

Meade, Ellen E., 2005, The FOMC: Preferences, Voting and Consensus, Federal Reserve Bank of St. Louis Review, 87, 93-101.

Meade, Ellen E. and David Stasavage, forthcoming, Publicity of Debate and the Incentive to Dissent: Evidence from the US Federal Reserve, Economic Journal.

Morris, Stephen, 2001, Political Correctness, Journal of Political Economy, 109, 231-265.

Mukhopadhaya, Kaushik, 2004, Jury Size and the Free Rider Problem, Journal of Law, Economics and Organization, 19, 24-44.

Nitzan, Shmuel and Jacob Paroush, 1982, Optimal Decision Rules in Uncertain Dichotomous Choice Situations, International Economic Review, 23, 289-297.

Ottaviani, Marco and Peter Norman Sørensen, 2001, Information aggregation in debate: who should speak first?, Journal of Public Economics, 81, 393-421.

Patacconi, Andrea, 2007, On the (Mis-)Use of Information for Public Debate, Oxford University. 
Persico, Nicola, 2004, Committee Design with Endogenous Information, Review of Economic Studies, 71, 165-191.

Perry, Motty and Larry Samuelson, 1994. Open- versus Closed-Door Negotiations, RAND Journal of Economics, 25, 348-359.

Prat, Andrea, 2005, The Wrong Kind of Transparency, American Economic Review, $95,862-877$.

Roberts, Alisdair, 2006, Dashed Expectations: Governmental Adaptation to Transparency Rules, Proceedings of the British Academy, 135, 107-125.

Sobel, Joel, 2006, Information Aggregation and Group Decisions, University of California, San Diego.

Stasavage, David, 2005, Does Transparency Make a Difference? The Example of the European Council of Ministers, London School of Economics.

Stasavage, David, 2007, Polarization and Publicity: Rethinking the Benefits of Deliberative Democracy, Journal of Politics, 69, 59-72.

Stiglitz, Joseph, 1998, Distinguished Lecture on Economics in Government: The Private Uses of Public Interests: Incentives and Institutions, Journal of Economic Perspectives, 12, 3-22.

Swank, Job, Otto H. Swank and Bauke Visser, 2007, How committees of experts interact with the outside world: some theory, and evidence from the FOMC.

Visser, Bauke and Otto H. Swank (2007), On Committees of Experts, Quarterly Journal of Economics, 122, 337-372.

Wernerfelt, Birger, 2007, Delegation, Committees, and Managers, Journal of Economics and Management Strategy, 16, 35-52.

Young, H. Peyton,1988, Condorcet's Theory of Voting, American Political Science Review, 82, 1231-1244. 